\title{
Avaliação da qualidade de méis de abelha produzidos e comercializados em Vitória da Conquista, Bahia
}

\section{Quality evaluation of bee honeys produced and marketed in Vitória da Conquista, Bahia, Brazil}

\author{
Manoel Nelson de Castro Filho* ${ }^{1}$, Jerffson Lucas Santos ${ }^{2}$, Ésio de Castro Paes ${ }^{3}$, Welliny Soares Rocha Dias ${ }^{1}$, Luanna \\ Fernandes Pereira ${ }^{1}$
}

\begin{abstract}
Resumo: O mel é um produto elaborado pelas abelhas, a partir do néctar das flores ou de secreções procedentes de partes vivas das plantas, que as abelhas recolhem, transformam e combinam com substâncias específicas próprias. Este alimento é nutritivo e energético, sendo apreciado, entre outros fatores, por suas propriedades terapêuticas. Açúcares, água, vitaminas, ácidos orgânicos e sais minerais são os principais constituintes do mel. Nesse sentido, as análises laboratoriais são utilizadas para inspeção, com o objetivo de conhecer a composição química do mel, identificando a qualidade do produto. O objetivo deste estudo foi avaliar a qualidade dos méis produzidos e comercializados na cidade de Vitória da Conquista - BA e sua adequabilidade em relação à identidade e qualidade padronizadas pela legislação brasileira. As amostras foram obtidas da Casa do Mel da Universidade Estadual do Sudoeste da Bahia, em Vitória da Conquista, e analisadas no laboratório de Química Analítica e Ambiental da mesma instituição. Foram analisados teor de umidade, acidez livre, açúcares redutores e não redutores, hidroximetilfurfural, sólidos solúveis totais, $\mathrm{pH}$ e reação de Fiehe e Lund em 18 amostras de méis. Das amostras avaliadas, 66,67\% apresentaram valores de HMF superiores aos aceitáveis pela legislação, 11,11\% para acidez e 27,78\% para o teste Fiehe. O resultado das demais análises apresentaram-se dentro dos valores permitidos.
\end{abstract}

Palavras-chave: Ácidos orgânicos; Análise físico-química; Apis mellifera; Melipona scutellaris; Tetragonisca angustula.

\begin{abstract}
The honey is a product elaborated by bees starting from the nectar of the flowers or from secretions from living parts of the plants, which the bees collect, transform, and combine with their own specific substances. This aliment is nutritious and energetic, being appreciated by its therapeutic properties. Sugars, water, vitamins, organic acids and mineral salts are the major constituints of honey. Therefore, laboratory analyzes are used for inspection, with the purpose to know the honey chemical composition, identifying product quality. This study aimed to evaluate the quality of honeys produced and comercialized in the city of Vitoria da Conquista - Ba, and its suitbality in relation to its standard identity and quality described by Brazilian lesgislation. The samples were obtained from the Casa do Mel (Honey House) in the State University of the Southwest of Bahia, in Vitoria da Conquista, and analized in the Analytical and Environmental Chemistry laboratory of the same institution. Moisture content, free acidity, reducing sugars and non-reducing sugars, hydroxymethylfurfural, total soluble solids, pH, and Fiehe and Lund reaction were analyzed for 18 honeys samples. Of the samples evaluated, 66,67\% had HMF values higher than those acceptable by the legislation, $11,11 \%$ for acidity and $27,78 \%$ for the Fiehe test. The result of excessive analyzes presented acceptable values.
\end{abstract}

Key words: Organic acids; Physico-chemical analysis; Apis mellifera; Melipona scutellaris; Tetragonisca angustula.

\footnotetext{
*Autor para correspondência

Recebido para publicação em 28/04/2017; aprovado em 21/09/2017

${ }^{1}$ Discente em Agronomia, Universidade Estadual do Sudoeste da Bahia, Vitória da Conquista, Bahia; Fone: (77) 998438426, E-mails: manoel_mrr@hotmail.com,wellinyrocha@gmail.com, luanna.gbi@hotmail.com

${ }^{2}$ Doutorando em Agronomia (Fitotecnia), Universidade Estadual do Sudoeste da Bahia, Vitória da Conquista, Bahia; E-mail: Je.lucas@hotmail.com

${ }^{3}$ Mestrando em Solos e Qualidade de Ecossistemas, Universidade Federal do Recôncavo da Bahia, Cruz das Almas, Bahia; E-mail: esiocastro@ hotmail.com
} 


\section{INTRODUÇÃO}

O mel é utilizado pelo homem de diversas maneiras, seja na forma de alimento, ou como medicamento, devido às suas propriedades antissépticas (CORTOPASSI-LAURINO; GELLI, 1991). No Brasil, ele ainda é pouco consumido, sua divulgação é pequena e a maioria da população só adquire o produto quando está com problemas de saúde.

O Brasil tem grande potencial para produção de mel, devido à presença de uma flora diversificada, grande extensão territorial e variação climática (ALMEIDA-FILHO et al., 2011), o que possibilita a produção de mel o ano todo. Este é um diferencial do Brasil em relação aos outros países, que, normalmente, coletam mel uma vez ao ano (MARCHINI et al., 2001).

Nos anos 2000, o país encontrava-se apenas na $27^{\mathrm{a}}$ posição do ranking mundial de exportação de mel. Já em 2004, houve um grande salto, e o país tornou-se o quinto maior exportador do produto (MANTILLA et al., 2012). Segundo o Instituto Brasileiro de Geografia e Estatística (IBGE, 2016), a produção brasileira chegou a 41.578 mil toneladas de mel em 2011, um aumento de 9,4\% em relação ao ano anterior, porém, em 2012, teve um recuo de aproximadamente 8 mil toneladas (MORAIS, 2013).

De acordo com a Instrução Normativa $\mathrm{n}^{\circ} 11$, de 20 de outubro de 2000 do Ministério da Agricultura, Pecuária e Abastecimento (BRASIL, 2000), mel é um produto alimentício produzido pelas abelhas melíferas, a partir do néctar das flores ou das secreções procedentes de partes vivas das plantas, que as abelhas recolhem, transformam, combinam com substâncias específicas próprias. Com isso, as propriedades físicas e químicas do mel dependem da abundância e da qualidade das flores no raio de ação das abelhas (NEVES et al., 2015).

$\mathrm{O}$ mel puro apresenta-se como um líquido, denso, viscoso e translúcido, de coloração variando entre o amarelo ao amarelo avermelhado, com sabor doce e característico. Dependendo da origem polínica pode variar a sua cor, aroma e demais composições físico-químicas, como açúcares, minerais, ácidos orgânicos, vitaminas, dentre outros compostos. Os resultados de pesquisa demostram que, além da composição florística a espécie de abelha também pode influenciar em diferença nos parâmetros físico-químicos do mel. Braghini et al. (2017) verificaram que houve diferença significativa entre méis de abelhas jataí (Tetragonisca angustula) frente aos méis de abelhas africanizadas (Apis mellifera) para os parâmetros como umidade, cinzas e hidroximetilfurfural. Para fins de comercialização, o mel pode ser classificado de acordo com sua origem botânica e procedimento de obtenção (BRASIL, 2000).

As análises físico-químicas no mel são de extrema importância, uma vez que garante o controle da qualidade do produto. Os resultados das análises são comparados com os padrões oficiais internacionais e com os estabelecidos pelo próprio país, com a finalidade de proteger o consumidor em não adquirir um produto adulterado ou de baixa qualidade (MARCHINI et al., 2004). A avaliação físico-química do mel é necessária, uma vez que este pode ter sua qualidade alterada durante o período de estocagem (SILVA et al., 2011).

O ácido ascórbico, também conhecido como vitamina C, que atua como um poderoso antioxidante, impedindo a oxidação do mel, na qual pode sofrer oxidação primeiro que outras moléculas, diminuindo dessa forma a qualidade do produto (PEREIRA, 2008). O ácido cítrico é outro importante componente presente no mel. Normalmente, os ácidos orgânicos sintéticos são usados nas indústrias alimentícias como aditivos (acidulantes e antioxidantes), na fabricação de refrigerante, sobremesa, conservas de frutas, doces e vinhos. O mesmo auxilia na retenção da carbonatação, potencializa os conservantes, confere sabor, prolonga a estabilidade da vitamina $\mathrm{C}$ e realça o aroma.

Este trabalho foi realizado com o objetivo de avaliar a qualidade de méis produzidos e comercializados no município de Vitória da Conquista - BA, observando-se as propriedades físico-químicas referentes à maturidade do produto (teor de açúcares redutores e não redutores, sacarose aparente, e umidade), à deterioração (níveis de acidez e de hidroximetilfurfural - HMF), teste de Lund e Fiehe, $\mathrm{pH}$ e ácidos orgânicos.

\section{MATERIAL E MÉTODOS}

Os méis utilizados nas determinações foram produzidos no Estado do Bahia, mais precisamente no município de Vitória da Conquista (14 $51^{\prime} 58^{\prime}$ ' de latitude Sul, e 40 50 ' $22^{\prime}$ ', de longitude oeste) (IBGE, 2014), elaborado predominantemente das floradas de plantas silvestres, aroeira e unha-de-gato. As amostras foram coletadas nos anos de 2014 a 2016. As análises físico-químicas foram realizadas no laboratório de Química Analítica e Ambiental da Universidade Estadual do Sudoeste da Bahia - Campus Vitória da Conquista, seguindo a metodologia da Portaria 01 MAPA/DAS de 07/10/1981, e a determinação dos ácidos orgânicos foram realizadas a partir de técnicas cromatográficas.

Os dados obtidos nas análises foram comparados aos parâmetros estabelecidos pelo Ministério da Agricultura, Pecuária e Abastecimento, apresentados na tabela 1.

Tabela 1. Parâmetros estabelecidos pelo Ministério da Agricultura, Pecuária e Abastecimento (BRASIL, 2000).

\begin{tabular}{|c|c|}
\hline Parâmetro & Mel Floral \\
\hline Açucares Redutores & Mínimo $65{\mathrm{~g} 100 \mathrm{~g}^{-1}}^{-1}$ \\
\hline Sacarose aparente & 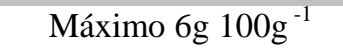 \\
\hline Umidade & 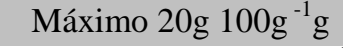 \\
\hline Acidez Livre & Máxima de $50 \mathrm{mEq} \mathrm{kg}{ }^{-1}$ \\
\hline $\mathrm{pH}$ & $3,3-4,6$ \\
\hline $\mathrm{HMF}$ & Máximo $60 \mathrm{mg} \mathrm{kg}^{-1}$ \\
\hline Sujidades & - \\
\hline
\end{tabular}

*Fonte: BRASIL, Instrução Normativa $N^{\circ}$. 11, de 20/10/2000.

Neste estudo, foram utilizadas 18 amostras de méis. Do total, 15 amostras eram de Apis mellífera L., sendo duas provenientes da florada de Aroeira (Schinus terebinthifolius Raddi), coletadas no mês outubro de 2014; uma proveniente da florada de Unha de Gato (Uncaria tomentosa), coletada em fevereiro de 2016; 12 amostras provenientes de florada silvestre, das quais, 3 foram coletadas em novembro/dezembro de 2015 e 9 em janeiro/fevereiro de 2016, uma amostra de Melipona scutellaris, coletada em janeiro de 2016, e 2 de Tetragonisca angustula, coletadas em dezembro de 2014 e 2015.

Determinação do pH: utilizou-se um pHmetro de bancada Digimed, modelo DM 20, seguindo a metodologia estabelecida pela Internacional Honey Commission. Pesou-se 
$10 \mathrm{~g}$ da amostra de mel e diluiu em $75 \mathrm{~mL}$ de água Milipure em seguida mediu-se o $\mathrm{pH}$ de cada amostra.

Teor de umidade $\mathrm{e}^{\circ}$ Brix: Para determinar os valores de umidade, utilizou-se um refratômetro ABBE de bancada Quimis, modelo: Q 767B, seguindo o método refratômetro de Chataway, revisado por Wedmore. Primeiramente faz-se uma calibração do aparelho com água Milipure. Em seguida adiciona-se uma gota de mel no refratômetro anotando-se cada resultado, esse processo foi realizado em triplicata para cada amostra. O valor encontrado é chamado de índice de refração. O princípio deste método consiste na determinação do índice de refração do mel a $20^{\circ} \mathrm{C}$, para cada grau acima dessa temperatura adiciona-se 0,00023 e subtrai-se este mesmo valor para cada grau abaixo da temperatura. $\mathrm{O}$ valor encontrado é convertido para o conteúdo de umidade através da tabela de Chataway ou pela fórmula de Wedmore (LACERDA et al., 2010).

Açúcares redutores: Foram determinados segundo o método do CAC (1990) a partir da modificação do procedimento de Lane e Eynon, envolvendo a redução da solução de Fehling, modificada por Soxhlet, durante a titulação no ponto de ebulição com uma solução de açúcares redutores do mel, usando-se azul de metileno como indicador.

Acidez Total: determinou-se a acidez seguindo o método $\mathrm{n}^{\text {o }} 962.19$ da AOAC (1998) e é conseguida por meio da determinação da acidez livre e lactônica. Para a determinação da acidez livre, titula-se a amostra com solução de $\mathrm{NaOH}$ $0,05 \mathrm{~N}$, até atingir o pH 8,5. Para a acidez lactônica, após a solução alcançar o $\mathrm{pH} 8,5$, pipeta-se $10 \mathrm{~mL}$ de $\mathrm{NaOH} 0,05 \mathrm{~N}$ e com $\mathrm{HCl} 0,05 \mathrm{~N}$ fez-se uma titulação de retorno até $\mathrm{pH} 8,3$ (WELKE et al., 2008). Para a conversão da acidez total tem se o cálculo: Acidez total = Acidez livre + lactônica.

Prova de Fiehe: esta prova foi realizada segundo as Normas analíticas do Instituto Adolfo Lutz. Pesou-se $5 \mathrm{~g}$ de mel em um béquer de $50 \mathrm{~mL}$, adicionou-se $5 \mathrm{~g}$ de éter etílico e agitou vigorosamente a mistura. Em seguida transferiu-se a camada etérea para um cadinho de porcelana, deixando evaporar a temperatura ambiente. Em seguida adicionou-se $5 \mathrm{~g}$ da solução de resorcina a $1 \%$, fazendo a leitura após 5 a 10 minutos (reação de cor).

Prova de Lund: esta prova foi realizada segundo as Normas analíticas do Instituto Adolfo Lutz. Utilizou-se 2 gramas de mel, diluindo-se em $20 \mathrm{~mL}$ de água destilada, em seguida foi transferido essa mistura para uma proveta de 50 $\mathrm{mL}$, onde se adicionou $5 \mathrm{~mL}$ de ácido tânico a $0,5 \%$, completou-se o conteúdo até $40 \mathrm{~mL}$. A leitura foi feita após 24 horas, observando o conteúdo precipitado.

Hidroximetilfurfural (HMF): foi determinado através do método quantitativo, que consiste na verificação do HMF, utilizando-se o método cromatográfico (CLAE). Utilizando bomba serie 200 , válvula de amostragem, "loop" de $20 \mu \mathrm{L}$ e um detector Serie 200 UV/VIS, Perkin Elmer (USA). A separação do analito foi realizada utilizando-se uma coluna $\mathrm{RP}$ - C18 (250 mm x 4,6 mm, $5 \mu \mathrm{m}$ de tamanho de película, Thermo, USA). O volume da amostra injetada foi de $20 \mu \mathrm{L}$, a qual foi submetida a uma eluição isocrática água/acetonitrila (80:20) e fluxo de $1 \mathrm{~mL} \mathrm{~min}^{-1}$, para o preparo da amostra pesou-se $5 \mathrm{~g}$ de mel e diluiu em água millipore (Milli-Q), em um balão volumétrico de $50 \mathrm{~mL}$. Em seguidas as amostras foram filtradas usando o filtro de seringa $0,45 \mu \mathrm{m}$ (Chromafil Xtra $25 \mathrm{~mm}$ de diâmetro e $0,2 \mathrm{~mm}$ de diâmetro de poro), e recolhidas em frascos de polietileno. Cada amostra foi analisada em triplicata.
Ácidos Orgânicos: para a determinação do teor de ácidos orgânicos (tartárico, ascórbico e cítrico) no mel, utilizou-se a cromatografia líquida de alta eficiência-CLAE, é composto de uma bomba serie 200, válvula de amostragem, "loop" de $20 \mu \mathrm{L}$ e um detector Serie 200 UV/VIS, Perkin Elmer (USA). Onde para a separação cromatográfica foi utilizada uma coluna de fase reversa C18 (250 x 4,6 mm, 5 $\mu \mathrm{m})$. A fase móvel utilizada para separação dos ácidos foi uma solução aquosa de $\mathrm{H} 2 \mathrm{O} / \mathrm{CH} 3 \mathrm{OH}$ (94:6), com $\mathrm{pH}$ ajustado para 2,1 com ácido fosfórico. Os padrões de ácidos orgânicos utilizados foram: Ácido ascórbico 99\% de pureza (Ecibra), Ácido cítrico 99,9\% de pureza (Belga Química), Ácido fumárico 99\% (Dinâmica), Ácido tartárico 99\% (Vetec). A água utilizada nas análises foi obtida do sistema Milli-Q (Millipore).

A identificação foi feita através dos tempos de retenção e a quantificação realizada por curva de padronização externa com 5 pontos para cada ácido orgânico. Para o preparo das amostras pesou-se $5 \mathrm{~g}$ da amostra de mel e diluiu em $25 \mathrm{~mL}$.

Análise estatística: A comparação entre as médias dos dados experimentais das análises de ácidos orgânicos, foram feitas pelo teste Scott-knott a 5\% de probabilidade.

\section{RESULTADOS E DISCUSSÃO}

A acidez do mel é decorrente da variação de ácidos orgânicos em sua composição, com destaque para o ácido cítrico, tartárico e ácido glicônico, sendo este último produzido pela ação da enzima glicose-oxidase (RIBEIRO et al., 2009).

Os valores de acidez livre nas amostras avaliadas variaram entre 26,00 (amostra I) e 55,00 mEq kg-1 (amostra D). Sendo que apenas as amostras H e D, de Apis mellifera, ultrapassaram o limite máximo de acidez preconizado pela legislação, que é de $50 \mathrm{mEq} \mathrm{kg}^{-1}$ (Tabela 2).

A variação na acidez das amostras de méis pode ter ocorrido em função da temperatura, visto que o parâmetro analisado sofre influência de fatores como: produção de ácidos por bactérias durante a maturação e quantidade de minerais presentes no mel (RICHTER et al., 2011), ou mesmo dos tipos de espécies vegetais utilizadas para a produção do mel, devido às diferenças nos néctares conferirem características específicas ao produto final (SANTOS; OLIVEIRA, 2013).

Valores acima do permitido pela legislação também foram encontrados por Aroucha et al. (2008) e Ribeiro et al. (2009). Nos respectivos trabalhos, a acidez variou de 31,25 a $86,75 \mathrm{mEq} \mathrm{kg}{ }^{-1}$ e de 15 a $63 \mathrm{mEq} \mathrm{kg}{ }^{-1}$, estando, neste último, $30 \%$ das amostras com a acidez acima de $50 \mathrm{mEq} \mathrm{kg}{ }^{-1}$. Esses estudos foram realizados no Rio Grande do Norte e Rio de Janeiro, respectivamente, regiões que apresentam temperaturas elevadas, outro fator também impactante na acidez.

A concentração de açúcares redutores nas amostras avaliadas variou de $68,03 \%$ a $75,19 \%$ (Tabela 2) e os teores de sacarose aparente variaram entre $1,52 \%$ a $5,09 \%$ (Tabela 2). De acordo com a legislação para méis de Apis mellifera, uma amostra deve conter no mínimo $65 \mathrm{~g}$ de açúcares redutores e máximo de $6 \mathrm{~g}$ de sacarose aparente em $100 \mathrm{~g}$ de amostra (BRASIL, 2001). Dessa forma, tanto o açúcar redutor como a sacarose aparente apresentaram valores dentro do limite especificado pela legislação. 
Tabela 2. Acidez livre, açúcares redutores, sacarose aparente, $\mathrm{pH}$, prova de Fiehe, prova de Lund, umidade, sólidos solúveis totais (SST) e hidroximetilfurfural (HMF) em méis produzidos e comercializados em Vitória da Conquista, Bahia.

\begin{tabular}{|c|c|c|c|c|c|c|c|c|c|c|}
\hline \multicolumn{2}{|c|}{$\begin{array}{c}\text { Amostras } \\
\text { (Dia de coleta) }\end{array}$} & $\begin{array}{c}\text { Acidez } \\
\text { Livre } \\
\mathrm{mEq} \mathrm{kg}^{-1}\end{array}$ & $\begin{array}{c}\text { Açúcares } \\
\text { redutores } \\
(\%)\end{array}$ & $\begin{array}{c}\text { Sacarose } \\
\text { aparente } \\
(\%)\end{array}$ & $\mathrm{pH}$ & $\begin{array}{l}\text { Prova } \\
\text { Fiehe }\end{array}$ & $\begin{array}{l}\text { Prova } \\
\text { Lund }\end{array}$ & $\begin{array}{l}\text { Umidade } \\
\qquad \%)\end{array}$ & $\begin{array}{c}\text { SST } \\
\left({ }^{\circ} \text { Brix }\right)\end{array}$ & $\begin{array}{c}\mathrm{HMF} \\
\left(\mathrm{mg} \mathrm{kg}^{-1}\right)\end{array}$ \\
\hline \multirow{15}{*}{$\begin{array}{c}\text { Apis } \\
\text { mellifera }\end{array}$} & A. $07 / 14$ & 42,50 & 70,17 & 1,52 & 4,62 & + & 1,60 & 17,20 & 81,00 & 1238,2 \\
\hline & B. $07 / 14$ & 32,50 & 68,03 & 2,15 & 4,34 & + & 2,25 & 17,80 & 80,50 & 310,40 \\
\hline & C. $11 / 15$ & 32,00 & $\mathrm{~N}$ & $\mathrm{~N}$ & 4,14 & - & 2,00 & 17,40 & 81,00 & 80,51 \\
\hline & D. $11 / 15$ & 55,00 & $\mathrm{~N}$ & $\mathrm{~N}$ & 3,82 & - & 2,85 & 19,10 & 79,75 & 125,22 \\
\hline & E. $12 / 15$ & 48,00 & $\mathrm{~N}$ & $\mathrm{~N}$ & 3,80 & + & 3,00 & 18,30 & 80,25 & 373,06 \\
\hline & F. $01 / 16$ & 37,50 & $\mathrm{~N}$ & $\mathrm{~N}$ & 4,02 & - & 1,85 & 19,40 & 79,00 & 56,84 \\
\hline & G. $01 / 16$ & 34,50 & $\mathrm{~N}$ & $\mathrm{~N}$ & 3,79 & - & 1,90 & 19,00 & 79,25 & 2,47 \\
\hline & Н. 01/16 & 52,00 & 70,92 & 3,15 & 4,19 & - & 1,40 & 17,50 & 81,00 & 46,57 \\
\hline & I. $01 / 16$ & 26,00 & $\mathrm{~N}$ & $\mathrm{~N}$ & 4,36 & - & 2,50 & 18,10 & 80,50 & 25,26 \\
\hline & J. $01 / 16$ & 48,50 & 74,07 & 2,55 & 3,95 & - & 3,10 & 17,60 & 80,75 & 3,60 \\
\hline & K. 02/16 & 42,50 & $\mathrm{~N}$ & $\mathrm{~N}$ & 3,82 & + & 4,40 & 19,40 & 79,00 & 242,59 \\
\hline & L. 02/16 & 50,00 & 70,92 & 3,15 & 3,91 & - & 3,10 & 18,60 & 79,75 & 170,95 \\
\hline & M. 02/16 & 43,00 & 75,19 & 3,86 & 3,58 & - & 2,00 & 17,70 & 80,50 & 25,13 \\
\hline & N. 02/16 & 40,00 & $\mathrm{~N}$ & $\mathrm{~N}$ & 3,77 & - & 3,10 & 18,00 & 80,50 & 36,39 \\
\hline & O. $02 / 16$ & 37,00 & $\mathrm{~N}$ & $\mathrm{~N}$ & 3,90 & + & 2,05 & 18,80 & 79,75 & 239,67 \\
\hline \multirow{2}{*}{$\begin{array}{l}\text { Tetragonisca } \\
\text { angustula }\end{array}$} & P. $12 / 14$ & 43,50 & 72,46 & 2,73 & 4,25 & - & 0,90 & 19,00 & 79,50 & 129,65 \\
\hline & Q. 12/15 & 43,50 & 69,69 & 2,52 & 4,23 & - & 0,75 & 19,20 & 79,25 & 144,32 \\
\hline $\begin{array}{l}\text { Melipona } \\
\text { scutellaris }\end{array}$ & R. 01/16 & 40,50 & 70,67 & 5,09 & 3,79 & - & 2,10 & 19,40 & 79,00 & 103,13 \\
\hline
\end{tabular}

$\mathrm{N}=$ amostras não analisadas devido à falta de materiais (reagentes).

Os valores encontrados no presente estudo foram similares aos encontrados por Santos e Oliveira (2013) 69,55 a $81,33 \%$, Braghini (2017) - 63,94 a 78,22\%, Alves et al. $(2011)-66,5$ a72,9\% e Richter et al. (2011) - 55,83\% a $70,21 \%$, para méis de Apis mellifera.

Santos e Oliveira (2013) argumentam que méis que apresentam níveis de açúcares redutores acima de $65 \%$ estão maduros para coleta.

Richter et al. (2011), ao analisarem o conteúdo de sacarose aparente em mel produzido na cidade de Pelotas RS, encontraram valores entre $0 \%$ e $1,76 \%$. Gomes (2009), ao realizar a caracterização e avaliação biológica de méis comerciais de Bragança, encontrou valores de sacarose aparente $\leq 5 \%$, corroborando com os resultados para este parâmetro, deste trabalho.

Teores de sacarose aparente (açucares não redutores) elevados são indicadores de uma coleta prematura do mel, isto é, a sacarose ainda não foi totalmente convertida em frutose e/ou glucose.

Os açúcares presentes nos méis são os responsáveis pela viscosidade, densidade, capacidade de granulação (cristalização), higroscopicidade e valor energético. Ele é o constituinte presente em maior quantidade do mel. Dentre os tipos de sacarídeos que compõem esse açúcar, têm-se aproximadamente, $38,5 \%$ de frutose, $31,3 \%$ de glicose, $7,2 \%$ de maltose, $1,5 \%$ de sacarose e $4,2 \%$ de oligossacarídeos (SHIN \& USTUNOL, 2005).

A composição de açúcares no mel está diretamente condicionada ao tipo de florada utilizada pelas abelhas, assim como pelas condições regionais e climáticas. Altas concentrações de sacarose podem ocorrer dependendo da origem botânica, ou podem indicar que o mel foi extraído prematuramente ou sofreu algum tipo de adulteração (RICHTER et al., 2011).

Silva et al. (2009), avaliaram as características físicoquímicas de méis produzidos em Limoeiro do Norte durante o armazenamento, em dois tipos de embalagens (plástica e metálica), durante 180 dias, e verificaram que houve aumento nos teores de açúcares redutores presente no mel. Este aumento deve-se, provavelmente, a transformação da sacarose em glicose e frutose provocada pela atividade da enzima invertase, já que a inativação desta enzima se dá pelo aquecimento do mel (RICHTER et al., 2011). Em ambas embalagens, o teor de sacarose aparente reduziu, apresentando valores de aproximadamente, 3,54\% de sacarose no tempo zero a 1,36\% em 180 dias de armazenamento. Essa transformação corresponde à explicação para a presença dos menores valores de sacarose aparente encontrados para as duas amostras coletadas no inverno de 2014, com valores de açúcar aparente de 1,52 e 2,15.

A análise de $\mathrm{pH}$ não é obrigatória para avaliação da qualidade do mel, no entanto, foi realizada como parâmetro complementar à avaliação da acidez total (Tabela 1). Os limites estabelecidos de $\mathrm{pH}$ para o mel são de 3,3 a 4,6, segundo a Portaria $n^{\circ} 6$ de 25/07/1985, do Ministério da Agricultura. Os valores de $\mathrm{pH}$ apresentados pelas amostras variaram entre 3,58 e 4,62, apresentando-se, todas as amostras, dentro dos limites estabelecidos pelo MAPA. Schlabitz et al. (2010) ao caracterizar físico-quimicamente e microbiologicamente amostras de mel da região do Vale do Taquari - RS, provenientes de diversas floradas encontrou valores de $\mathrm{pH}$ de todas as amostras analisadas dentro dos valores permitidos pela legislação.

A Prova de Fiehe se caracteriza como um teste, com o qual indica se a concentração de hidroximetilfurfural presente na amostra está maior ou menor que $200 \mathrm{mg} \mathrm{kg}^{-1}$. Ao realizar o teste, ele poderá apresentar coloração amarela (teste negativo - HMF menor que $200 \mathrm{mg} \mathrm{kg}^{-1}$ ), ou vermelha (teste positivo - HMF maior que $200 \mathrm{mg} \mathrm{kg}^{-1}$ ). Como ele é um teste qualitativo não há a possibilidade de saber a quantidade exata do HMF na amostra.

Das amostras analisadas, 27,78\% apresentaram resultados positivo para a Prova de Fiehe (Tabela 2). As amostras que apresentaram resultados negativos para este teste não significa que estão livre de $\mathrm{HMF}$, apenas apresentaram teores abaixo de $200 \mathrm{mg} \mathrm{kg}^{-1}$, sendo a presença máxima permitida na legislação a quantidade de $60 \mathrm{mg} \mathrm{kg}^{-1}$. 
Ao avaliar a qualidade e a autenticidade de méis no município de São João de Meriti - RJ, Martins et al. (2014) identificaram resultado positivo na Prova de Fiehe em todas as amostras analisadas, indicando uma possível adulteração dos produtos pela adição de altos teores de sacarose. Almeida-Filho et al. (2011) indicaram 90\% de reprovação dos méis comercializado no município de Pombal-PB, caracterizando um possível superaquecimento ou armazenamento prolongado.

A Prova de Lund, ocorre através da reação de precipitação de proteínas através do ácido tânico $0,5 \%$. Os valores obtidos compreenderam um intervalo de 0,75 a 4,40 $\mathrm{mL}$. Sendo que, das amostras analisadas, 22,22\% (L, K, N e J) apresentaram valores acima da média (Tabela 2). Para a identificação de um mel de alto grau de pureza, o resultado encontrado deve estar situado numa faixa de 0,6 a $3,0 \mathrm{~mL}$ (INSTITUTO ADOLFO LUTZ, 2008).

Almeida-Filho et al. (2012), analisando amostras comercializadas em Campo Grande - MS, constataram que $90 \%$ não apresentaram volume de precipitado e destacaram a ausência de substâncias proteicas no alimento, enquanto que Martins et al. (2014) avaliando a qualidade e a autenticidade de méis no município de São João de Meriti-RJ, encontraram valores dentro do estabelecido, indicando que as amostras podem ser consideradas produtos de boa qualidade.

A umidade (teor de água) é uma das características mais importantes no mel, representando o segundo componente em quantidade, variando conforme o clima de cada região, o tipo de floração e a época de colheita. Ele pode influenciar no sabor, viscosidade, fluidez e também na conservação do produto, sendo um dos indicativos do processo de fermentação.

Os teores de umidade de todas as amostras avaliadas estavam em conformidade com os padrões estabelecidos pela legislação para méis de Apis mellifera, apresentando resultados inferiores a 20\% (BRASIL, 2000), sugerindo que os produtos tiveram boa maturação (Tabela 1). Resultado semelhante foi encontrado por Dias et al. (2009), que ao compararem 6 amostras de méis, 3 industrializadas e 3 adquiridas de vendedores ambulantes em Londrina-PR, concluíram que todas as amostras estavam em conformidade com os padrões estabelecidos pela legislação. Já Richter et al. (2011), encontraram valores de umidade entre 15,5 e $20,9 \%$, sendo que das 19 amostras avaliadas, uma amostra que corresponde a 5,2\% do total avaliado apresentou teor superior ao preconizado pela legislação e uma amostra apresentou o conteúdo máximo permitido. Abadio Finco et al. (2010) avaliando 24 amostras provenientes de 13 associações de apicultores da região Sul do Estado do Tocantins, encontraram resultados entre 18,9 a $21 \%$, e observaram que $33,3 \%$ das amostras avaliadas apresentaram valores superiores ao limite preconizado. Moraes et al. (2014), avaliando o parâmetro de umidade, verificou que apesar de não ter apresentado diferença significativa entre os valores encontrados para os dois municípios, os mesmos ficaram acima do limite estabelecido pela legislação (20\%) em 8 amostras do município de Santa Helena e em 7 de Terra Roxa, totalizando $37,5 \%$ das amostras.

Segundo Ribeiro et al. (2009), valores de umidade acima do limite estabelecido na legislação, podem ser indicativos de um processo fermentativo ocasionado por uma colheita inadequada, ou seja, méis ainda não-maduros, que as abelhas ainda não opercularam. O excesso de umidade no mel favorece a desenvolvimento de leveduras, levando o produto a uma fermentação, tornando-o impróprio para consumo e impossibilitando a sua comercialização. Dessa forma, é necessário sempre avaliar as condições de processamento e armazenamento das amostras, de forma a identificar uma possível causa dos elevados valores de umidade encontrados nas amostras.

Devido ao mel ser composto essencialmente por hidratos de carbono, a análise de sólidos solúveis totais é um bom indicador da composição de açúcares (SILVA et al., 2003). Os valores de sólidos totais encontrados nas análises apresentaram valores entre 79,0\% e $81,0 \%$ (medidos em ${ }^{\circ}$ Brix). De acordo com a FCUP/FCNAUP, parâmetros de avaliação da qualidade do mel e percepção do risco pelo consumidor 36 Diretiva 2001/110/CE, de 20 de dezembro, o

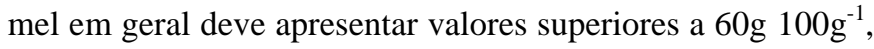
com exceção do mel de melada, cujo teor deve ser igual ou

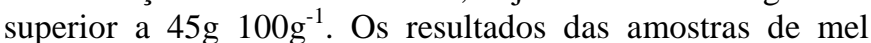
estão de acordo com os limites estabelecidos na diretiva europeia. $\mathrm{O}$ valor encontrado nas análises representa o índice de refração expresso em percentagem de sacarose. As amostras de mel são bastante semelhantes em relação às quantidades de sólidos solúveis. Bera (2004) encontrou valores de $77,7 \%$ a $80,2 \%$ de ${ }^{\circ}$ Brix para mel com própolis. Estes resultados são, em parte, inferiores aos encontrados para as amostras do presente trabalho, o que confirma mais uma vez que o clima, a origem floral e o local de origem do mel têm grande influência nas propriedades final do mel.

$\mathrm{O}$ hidroximetilfurfural (HMF) no mel é formado através da reação entre açúcares e ácidos. A sua proporção na amostra pode aumentar com a elevação da temperatura, armazenamento e adição de açúcar invertido, podendo também ser afetado pela acidez, $\mathrm{pH}$, água e outros constituintes do mel. O HMF é um indicador de qualidade do mel, visto que, quando elevado, o mel apresenta queda no seu valor nutritivo, devido à destruição de algumas vitaminas e enzimas por meio de aquecimento.

A avaliação do hidroximetilfurfural (HMF), acidez e atividade diastásica, são as análises recomendadas pela legislação brasileira para avaliação de degradação. Segundo Saraiva et al. (2013), para o mel, o HMF é o produto de degradação mais comum, indicando "envelhecimento" do produto.

Os valores do hidroximetilfurfural quantificados ficaram entre 2,47 (amostra G) e 1238,28 (amostra A). 66,67\% das amostras apresentaram valores superiores ao máximo permitido pela legislação (BRASIL, 2000), que é de $60 \mathrm{mg}$ $\mathrm{kg}^{-1}$. Esse resultado deve-se, principalmente, ao tempo de armazenamento das amostras, sendo que valores elevados foram encontrados nas amostras A e B, as quais foram coletadas em 2014, corroborando com a colocação de Saraiva et al. (2013), ao avaliar a presença e o grau de deterioração dos méis de abelha comercializados em São Luís - MA.

Dentre as que apresentaram resultados positivos ao teste, além das amostras C, J coletadas no mês 07/2014, estão as amostras H, M e N, coletadas em dezembro de 2015 e fevereiro de 2016 respectivamente, demonstrando que o teor de HMF não foi influenciado apenas pelo tempo de armazenamento, podendo o mesmo ter variado também devido ao tipo de florada e/ou forma de armazenamento. Segundo Leal (2014), as condições climáticas da região também interferem nos valores de HMF. Saraiva et al. (2013) encontraram média de $66,99 \mathrm{mg} \mathrm{kg}^{-1}$ de hidroximetilfurfural 
nas amostras avaliadas, valor este acima do máximo permitido pela legislação. Já Leal (2014), ao avaliar os atributos sensoriais de 21 amostras de méis coletadas em propriedades apícolas da região de Londrina, verificou que os valores de todas as amostras apresentaram dentro do valor máximo permitido. Silva (2013), também encontrou valores dentro dos limites permitidos em méis de capixingui e silvestre, da região de Ortigueira $-\mathrm{PR}$.
Os valores de ácidos nas amostras apresentaram-se muito variáveis (Tabela 3). Isso ocorre por que os teores de ácidos orgânicos nas amostras dependem do tipo da espécie botânica, época de floração, tempo de armazenamento e espécie de abelha. Neste trabalho, por exemplo, a amostra de Melipona scutellaris (Uruçu), apesar de coletada em 2016 apresentou valores baixos para todos os ácidos analisados.

Tabela 3. Teores de ácido tartárico, ascórbico e cítrico em amostras de méis produzidas e comercializadas em Vitória da Conquista, Bahia.

\begin{tabular}{|c|c|c|c|c|c|c|c|}
\hline \multirow{3}{*}{$\begin{array}{c}\text { Classificação } \\
\text { Mel (Apis mellifera) } \\
\text { Planta: Aroeira }\end{array}$} & \multirow{2}{*}{$\begin{array}{c}\begin{array}{c}\text { Identificação } \\
\text { (dia da coleta) }\end{array} \\
04 / 07 / 2014\end{array}$} & \multicolumn{2}{|c|}{$\begin{array}{l}\text { Ácido Tartárico } \\
\left(\mathrm{mg} \mathrm{kg}^{-1}\right)\end{array}$} & \multicolumn{2}{|c|}{$\begin{array}{l}\text { Ácido Ascórbico } \\
\left(\mathrm{mg} \mathrm{kg}^{-1}\right)\end{array}$} & \multicolumn{2}{|c|}{$\begin{array}{l}\text { Ácido Cítrico } \\
\left(\mathrm{mg} \mathrm{kg}^{-1}\right)\end{array}$} \\
\hline & & 18804.19 & $\mathrm{~F}$ & 98.75 & $\mathrm{E}$ & 369.19 & $\mathrm{C}$ \\
\hline & 04/07/2014 & 23459.44 & $\mathrm{E}$ & $<\mathrm{LQ}$ & & 356.71 & $\mathrm{C}$ \\
\hline \multirow{3}{*}{$\begin{array}{l}\text { Mel (Apis mellifera) } \\
\text { Planta: Silvestre }\end{array}$} & $14 / 11 / 2015$ & 23202.19 & $\mathrm{E}$ & $<\mathrm{LQ}$ & & 474.13 & B \\
\hline & $17 / 11 / 2015$ & 33676.79 & $\mathrm{C}$ & 3384.46 & B & 282.80 & $\mathrm{C}$ \\
\hline & $07 / 12 / 2015$ & 36699.15 & B & 91.89 & $\mathrm{E}$ & 97.57 & $\mathrm{E}$ \\
\hline \multirow{9}{*}{$\begin{array}{l}\text { Mel (Apis mellifera) } \\
\text { Planta: Silvestre }\end{array}$} & $15 / 01 / 2016$ & 14606.23 & $\mathrm{G}$ & 6.89 & $\mathrm{~F}$ & 66.08 & $\mathrm{E}$ \\
\hline & $15 / 01 / 2016$ & 40330.72 & A & 4074.97 & A & 241.33 & $\mathrm{D}$ \\
\hline & $25 / 01 / 2016$ & 16391.59 & G & 18.64 & $\mathrm{~F}$ & $<\mathrm{LQ}$ & \\
\hline & $30 / 01 / 2016$ & 25375.69 & $\mathrm{E}$ & 162.57 & $\mathrm{D}$ & 243.36 & $\mathrm{D}$ \\
\hline & $30 / 01 / 2016$ & 28668.25 & D & 2864.71 & $\mathrm{C}$ & 64.05 & $\mathrm{E}$ \\
\hline & $12 / 02 / 2016$ & 18842.03 & $\mathrm{~F}$ & $<\mathrm{LQ}$ & & 72.78 & $\mathrm{E}$ \\
\hline & $18 / 02 / 2016$ & 25258.85 & $\mathrm{E}$ & $<\mathrm{LQ}$ & & 93.05 & $\mathrm{E}$ \\
\hline & $18 / 02 / 2016$ & 28047.42 & D & 87.31 & $\mathrm{E}$ & 343.93 & $\mathrm{C}$ \\
\hline & $23 / 02 / 2016$ & 24112.47 & $\mathrm{E}$ & 202.28 & $\mathrm{D}$ & 677.76 & A \\
\hline $\begin{array}{l}\text { Mel (Apis mellifera) } \\
\text { Planta: Unha de Gato }\end{array}$ & $29 / 02 / 2016$ & 20798.44 & $\mathrm{~F}$ & $<\mathrm{LQ}$ & & 510.30 & B \\
\hline \multirow{2}{*}{$\begin{array}{c}\text { Mel de (Tetragonisca } \\
\text { angustula) } \\
\text { Planta: } \text { Silvestre }\end{array}$} & $10 / 12 / 2014$ & 6216.17 & $\mathrm{H}$ & 90.58 & $\mathrm{E}$ & 334.11 & $\mathrm{C}$ \\
\hline & $10 / 12 / 2015$ & 38709.45 & A & 241.75 & $\mathrm{D}$ & 228.39 & D \\
\hline $\begin{array}{l}\text { Mel (Melipona } \\
\text { scutellaris) } \\
\text { Planta: Silvestre }\end{array}$ & $05 / 01 / 2016$ & 21373.79 & $\mathrm{~F}$ & 69.31 & $\mathrm{E}$ & 83.38 & $\mathrm{E}$ \\
\hline $\mathrm{CV} \%$ & & 6.23 & & 7.88 & & 20.48 & \\
\hline
\end{tabular}

Médias seguidas de mesma letra na coluna não diferem entre si pelo teste de Scott-knott a $5 \%$ de probabilidade. $<$ LQ $=$ valor menor que o limite de quantificação.

Dos ácidos analisados, o tartárico foi o que apresentou em maior quantidade. Este ácido têm a função de conservar o alimento por mais tempo, além de quebrar a sacarose em glicose e frutose, agindo como a enzima invertase das abelhas.

O teor de ácido ascórbico (Vitamina C) apresentou grande variação dentre as amostras e foi encontrado em menor quantidade em relação aos demais ácidos estudados devido aos méis apresentarem relativamente baixas concentrações as quais ainda sofrem degradação com o tempo de armazenamento. Segundo Martins et al. (2009), o teor de vitamina C no mel, é consideravelmente baixo. Spath (2013), avaliando compostos bioativos em amostras de méis de Melipona scutellaris, verificou diferença significativa no teor de ácido ascórbico em 4 amostras analisadas, sendo apresentadas variações entre 8,1 e $67,84 \mathrm{mg} / 100 \mathrm{~g}$ com média de $26,56 \mathrm{mg} / 100 \mathrm{~g}$, valores esses superiores ao deste estudo. Esta característica é pouco avaliada em méis de abelhas nativas, porém tem variações registradas por Oliveira et al. (2006), que, estudando méis de diferentes Meliponíneos paraenses encontrou variação de 1,04 a $8,28 \mathrm{mg} / 100 \mathrm{~g}$, Kishore et al. (2011), ao analisarem méis de abelhas de espécies nativas da Malásia, encontraram variações entre
13,92 e 36,5 mg/100g de ácido ascórbico em méis de diferentes origens florais.

As amostras coletadas em 2014 apresentaram valores relativamente baixos para todos os ácidos, principalmente ácidos tartárico e cítrico. Isto acontece porque, como o passar do tempo, esses ácidos orgânicos se oxidam. Em relação ao teor de ácido tartárico, as amostras de mel de Apis melífera, coletadas em 15 de janeiro de 2016, e de Tetragonisca angustula, coletadas em 10 de dezembro 2015, foram as que apresentaram, estatisticamente, melhores valores.

Os ácidos orgânicos se oxidam e degradam, ocorrendo perdas significativas em suas concentrações ao passar do tempo. Geralmente, os teores de ácidos orgânicos diminuem devido aos mesmos atuarem como importantes fontes de energia respiratória, os quais são convertidos ou oxidados em açúcares. Alguns fatores que podem afetar a degradação dos ácidos orgânicos, principalmente a vitamina $\mathrm{C}$ são: condições de estocagem, tipo de embalagem, oxigênio, luz, catalisadores metálicos, enzimas e pH. Além disso, alguns autores também relatam que a carga microbiana e a concentração inicial de sais podem influenciar na degradação da vitamina C (ÖZKAN et al., 2004).

Dentre os ácidos utilizados em bebidas, comidas, na área farmacêutica, entre outros exemplos, o cítrico possui um 
importante papel, possuindo uma produção e comercialização de milhões de toneladas que cresce anualmente (MARMITT et al., 2016).

\section{CONCLUSÕES}

A maioria das amostras de méis produzidas em Vitória da Conquista atendem aos padrões de qualidade estabelecidos pela legislação brasileira para méis de Apis mellifera.

Os resultados dos parâmetros físico-químicos não indicaram diferença entres os méis de Apis mellifera e abelhas nativas.

O HMF apresentou pior qualidade dentre os parâmetros avaliados, para a maioria dos méis.

\section{REFERÊNCIAS}

ABADIO FINCO, F. D. B.; MOURA, L. L.; SILVA, I. G. Propriedades físicas e químicas do mel de Apis mellifera L. Revista Ciência e Tecnologia de Alimentos, Campinas, v. 30, n. 3, p.706-712, 2010. http://dx.doi.org/10.1590/S010120612010000300022.

ALMEIDA-FILHO, J. P.; MACHADO, A. V.; ALVES, F. M. S.; QUEIROGA, K. H.; CÂNDIDO, A. F. M. Estudo Físicoquímico e de qualidade do mel de abelha comercializado no município de Pombal - PB. Revista Verde, Mossoró, v.6, n.3, p.83-90, 2011.

ALVES, T. T. L.; SILVA, J. N.; MENESES, A. R. V. de; HOLANDA NETO, J. P. de. Caracterização físico-química e avaliação sensorial dos méis produzidos por abelhas Apis mellifera L. oriundos de diversas floradas da região do Cariri cearense. Revista Verde, Mossoró, v.6, n.2, p.169-175, 2011.

AOAC. Official methods of analysis of AOAC International: Agricultural chemicals, contaminants, drugs. 16. ed., v. 1. Gaithersburg: AOAC International, 1998.

AROUCHA, E. M. M.; OLIVEIRA, A. J. F.; NUNES, G. H. S.; MARACAJA, P. B.; SANTOS, M. C. A. Qualidade do mel de abelha produzido pelos incubados da Iagram e comercializado no município de Mossoró/RN. Revista Caatinga, Mossoró, v.21, n.1, p. 211-217, 2008.

BERA, A. Composição físico-química do mel adicionado com própolis. Universidade de São Paulo. 2004. 68f. Dissertação (Mestrado em Ciência dos alimentos) Faculdade de Ciências Farmacêuticas da Universidade de São Paulo, São Paulo. 2004.

BRAGHINI, F.; CHIAPETTI, E. S.; JÚNIOR, J. F.; MILESKI, J. P. F.; OLIVEIRA, D. F.; MORÉS, S.; COELHO, A. R.; TONIAL, I. B. Qualidade dos méis de abelhas africanizadas (Apis mellifera) e jataí (Tetragonisca angustula) comercializado na microrregião de Francisco Beltrão - PR. Revista de Ciências Agrárias, v.40, n1, p. 279289, 2017. http://dx.doi.org/10.19084/RCA16039.

BRASIL. Instrução Normativa $n^{\circ} 11$, de 20 de outubro de 2000. Estabelece o regulamento técnico de identidade e qualidade do mel. Diário Oficial da República Federativa do Brasil, Brasília, 2000.
BRASIL. Ministério da Agricultura, Pecuária e Abastecimento. Instrução normativa n. 11, de 20/10/2000. Padrão de identidade e qualidade do mel. Diário Oficial da República Federativa do Brasil, Brasília, 2001.

CODEX ALIMENTARIUS COMISSION. Codex standards for sugars (honey). Rome: FAO, 1990.

CORTOPASSI-LAURINO, M.; GELLI, D. S. Analyse pollinique, propriétes physico-chimiques et action antibactérienne des miels d'abeilles africanisées Apis mellifera et de Méliponinés du Brésil. Apidologie, Paris, v.22, n.1, p.61-73, 1991. https://doi.org/10.1051/apido:19910108.

DIAS, J. S.; CAMARGO, A. C.; BARIN, C. S.; ELLENSOHN, R. M. Caracterização Físico-Química de amostras de Mel. Científica Ciências Exatas e Tecnológicas, Londrina, v. 8, n. 1, p. 19-22, 2009.

GOMES, S. P. M. Caracterização e avaliação biológica de méis comerciais. 2009. 67f. Dissertação (Mestrado em Qualidade e Segurança Alimentar) - Instituto Politécnico de Bragança, Escola Superior Agrária, Bragança. 2009.

$\begin{array}{lll}\text { IBGE - INSTITUTO BRASILEIRO DE GEOGRAFIA E } \\ \text { ESTATÍSTICA. } & \text { Cidades. } & \text { Disponível em: }\end{array}$ <http://www.cidades.ibge.gov.br> Acesso em 20 de jul. de 2016.

INSTITUTO ADOLFO LUTZ. Métodos físico-químicos para análise de alimentos. 4.ed. São Paulo, 2008. p.281-343.

KISHORE, R. K.; HALIM, A. S.; SYAZANA, M. S.; SIRAJUDEEN, K. N. S. Tualang honey has higher phenolic content and greater radical scavenging activity compared with other honey sources. Nutrition Research, v. 31, n. 4, p. 322325, 2011. DOI: 10.1016/j.nutres.2011.03.001.

LACERDA, J. J. J.; SANTOS, J. S.; SANTOS, S. A.; RODRIGUES, G. B.; SANTOS, M. L. P. Influência das características físico-químicas e composição elementar nas cores de méis produzidos por Apis mellifera no sudoeste da Bahia utilizando análise multivariada. Química Nova, São Paulo, v.33, n.5, p.1022-1026, 2010. http://dx.doi.org/10.1590/S0100-40422010000500003.

LEAL, S. F. L. S. Análise sensorial do mel usando a técnica de perfil livre e sua aplicação em concursos de mel. 2014. 46 f. Trabalho de Conclusão de Curso (Graduação) Universidade Tecnológica Federal do Paraná, Londrina, 2014.

LOPES, V. R. Ácido Ascórbico - características, mecanismos de atuação e aplicações na indústria de alimentos. 2008. $39 f$. Trabalho acadêmico apresentado ao Curso de Bacharelado em Química de Alimentos. Universidade Federal de Pelotas, Pelotas, 2008.

MANTILLA, S. P. S.; SANTOS, E. B.; BARROS, L. B.; FREITAS, M. Q. Análise descritiva quantitativa aplicada em mel de abelhas (Apis mellifera): Uma revisão. Colloquium Agrariae, Presidente Prudente, v. 8, n.2, 2012. 10.5747/ca.2012.v08.n2.a081. 
MARCHINI, L. C.; MORETI, A. C. C.; SILVEIRA NETO, S. Características físico-químicas de amostras de mel e desenvolvimento de enxames de Apis mellifera L., 1758 (Hymenoptera, Apidae), em cinco diferentes espécies de eucaliptos. Bol. CEPPA, Curitiba, v.21, n.1, p.193-206, 2001. http://dx.doi.org/10.5380/cep.v21i1.1159.

MARMITT, L. G.; BETTI, J.; OLIVEIRA, E. C. Determinação de ácido cítrico e pH em diferentes cultivares de limão e marcas de sucos artificiais de limão em pó Destaques Acadêmicos, Lajeado, v. 8, n. 4, p. 245-252, 2016. http://dx.doi.org/10.22410/issn.2176-3070.v8i4a2016.1226.

MARTINS, W. L. D.; ALBUQUERQUE, D. S.; AZEVEDO, L. C.; FRANCO, T. C. R. S. Avaliação das propriedades de um composto a base de mel de abelhas e extrato de acerola. Revista Científica - Cadernos de Pesquisa, São Luís, p. 25-30, 2009.

MARTINS, V. C.; AQUINO, G. A. S.; MARQUES, C. A.; TORRES, J. C. Avaliação da qualidade de méis comercializados no município de São João de Meriti, RJ. Revista Perspectivas da Ciência e Tecnologia, v.6, n.1/2, p.14-21, 2014

MORAES, F. J.; GARCIA, R.C.; VASCONCELOS, E.; CAMARGO, S.C.; PIRES, B.G.; HARTLEBEN, A.M.; LIESENFELD, F.; PEREIRA, D.J.; MITTANCK, E.S.; GIASSON, J.; GREMASCHI, J.R. Caracterização físicoquímica de amostras de mel de abelha africanizada dos municípios de Santa Helena e Terra Roxa (PR). Arquivo Brasileiro de Medicina Veterinária e Zootecnia, v.66, n.4, p.1269-1275, 2014. http://dx.doi.org/10.1590/1678-6865.

MORAES, V. P. P. Produção brasileira de mel recua em 2012. Revista Safra. Disponível em $<$ http://revistasafra.com.br/producao-brasileira-de-mel-recuaem-2012/>. Publicado em 07 de novembro de 2013.

NEVES, A. P. M.; ALMEIDA, A. M. B.; MACHADO, A. V.; COSTA, R. O. Análise físico-química e microbiológica do mel de abelha. Revista Brasileira de Agrotecnologia, Garanhuns, PE, v.5, n.1, p. 14-18, 2015.

OLIVEIRA, G. A.; SODRE, G. S.; CARVALHO, C. A. S.; SOUZA, B. A.; CAVALCANTE, S. M. P.; FONSECA, A. A. O. Análises físico-químicas de méis de Melipona quadrifasciata do semi-árido da Bahia. In: CONGRESSO BRASILEIRO DE APICULTURA, 16, 2006. Anais... Aracajú: Confederação Brasileira de Apicultura, 2006.

ÖZKAN, M.; AYSEGÜL, K.; CEMEROGLU, B. Effects of hydrogen peroxide on the stability of ascorbic acid during storage in various fruit juices. Food Chemistry, Chicago, $\begin{array}{llll}\text { v.88, n.4, } & \text { p. } & \text { 591-597, } & 2004 .\end{array}$ https://doi.org/10.1016/j.foodchem.2004.02.011

PEREIRA, V. R. Ácido Ascórbico - características, mecanismos de atuação e aplicações na indústria. 2008. 39f. Trabalho acadêmico apresentado ao Curso de Bacharelado em Química de Alimentos. Universidade Federal de Pelotas, Pelotas. 2008.
RIBEIRO, R. O. R.; SILVA, C.; MONTEIRO, M. L.; BAPTISTA, R. F.; GUIMARÃES, C. F. MÁRSICO, E. T.; MANO, S. B.; PARDI, H. S. Avaliação comparativa da qualidade físico-química de méis inspecionados e clandestinos, comercializados no estado do Rio de Janeiro, Brasil. Revista Brasileira de Ciência Veterinária, Niterói, v.16, n. $1, \quad$ p. $3-7, \quad 2009$. http://dx.doi.org/10.22409/rbcv.v16i1.339.

RICHTER, W.; JANSEN, C.; VENZKE, T. S. L.; MENDONÇA, C. R. B.; BORGES, C. D. Avaliação da qualidade físico-química do mel produzido na cidade de Pelotas/RS. Alimentos e Nutrição, Araraquara, v.22, n.4, p.547-553, 2011.

SANTOS, D. C.; OLIVEIRA, E. N. A. Características físicoquímicas e microbiológicas de méis de Apis mellifera L. provenientes de diferentes entrepostos. Comunicata Scientiae, Bom Jesus, v.4, n.1, p.67-74, 2013.

SARAIVA, M. A.; NUNES, G. S.; ROSA, I. G.; SILVA, J. M.; PEIXOTO, C. R.; HOLANDA, C. A. Estado de deterioração dos méis de abelha (Apis mellifera) comercializados em São Luís do Maranhão. Cadernos de Pesquisa, São Luís, v. 20, n. 1, p.64-68, 2013. http://dx.doi.org/10.18764/2178-2229.v20.n1.p.64-68.

SCHLABITZ, C.; SILVA, S. A. F.; SOUZA, C. F. V. Avaliação de parâmetros físico-químicos e microbiológicos em mel. Revista Brasileira de Tecnologia Agroindustrial, Paraná, v.4, n.1, p.80-90, 2010. DOI: 10.3895/S198136862010000100009 .

SHIN, H.; USTUNOL, Z. Carbohydrate composition of honey from different floral sources and their influence on growth of selected intestinal bacteria: an in vitro comparison. Food Research International, Selangor, v.38, n.6, p.721-728, 2005. https://doi.org/10.1016/j.foodres.2005.01.007.

SILVA, C. V. da. Características físico-químicas de mel de capixingui e silvestre da região de Ortigueira-Pr. 2013. 33 f. Trabalho de Conclusão de Curso (Graduação) - Universidade Tecnológica Federal do Paraná, Londrina, 2013.

SILVA, R. D. N., MONTEIRO, V. N., ALCANFOR, J. D. A. X., ASSIS, E. M. E ASQUIERI, E. R. Comparação de métodos para a determinação de açúcares redutores e totais em mel. Ciência e Tecnologia de Alimentos, Campinas, v.23, n.3, p.337-341, 2003. http://dx.doi.org/10.1590/S010120612003000300007.

SILVA, M. B. L.; CHAVES J. B. P.; VALENTE, M. E. R.; GOMES, J. C.; OLIVEIRA, G. F.; MESSAGE, D. Qualidade de méis produzidos por apicultores e méis provenientes de entrepostos registrados no Serviço de Inspeção Federal. Arquivo Brasileiro de Medicina Veterinária e Zootecnia, v.63, n.4, p.1043-1045, 2011. http://dx.doi.org/10.1590/S010209352011000400037 .

SILVA, K. F. N. L.; QUEIROZ, A. J. M.; FIGUEIREDO, R. M. F.; SILVA, C. T. S.; MELO, K. S. Características físicoquímicas de mel produzido em limoeiro do norte durante o armazenamento. Revista Caatinga, Mossoró, v.22, n.4, p.246254, 2009. 